\title{
"Tu sabe do que eu tô falando": a variação pronominal da segunda pessoa do singular em Florianópolis, um estudo de caso
}

\author{
"You know what I'm talkin \\ about": second-person singular \\ pronoun variation in \\ Florianópolis, a case study
}

Rafael Zaccaron ${ }^{1}$

http://orcid.org/0000-0001-7796-501X

RESUMO: Há variação no uso do pronome pessoal da segunda pessoa $t u / v o c e ̂$ no português brasileiro. Neste artigo, discute-se a relevância dos fatores faixa etária e localidade no uso dos pronomes pessoais tu/você em Florianópolis-SC. Tendo como base os conceitos da Teoria da Variação de Labov (2008), a análise de duas entrevistas semiestruturadas com duas florianopolitanas procura identificar os fatores linguísticos e sociais que induzem tal fenômeno linguístico. Os resultados deste estudo de caso indicam variabilidade no uso do pronome tu e você na cidade. Sendo que o pronome tu é relacionado ao vernáculo enquanto você é considerado o pronome de uso para desconhecidos ou no ambiente de trabalho, segundo as participantes.

Palavras-chave: Sociolinguística; pronomes de segunda pessoa; variação tu/você.

1 Mestre em Inglês pela Universidade Federal de Santa Catarina (UFSC). E-mail: rafaelzaccaron@gmail.com 
ABSTRACT: There is variation in Brazilian Portuguese when it comes to the use of second-person pronouns $t u$ /você. In this paper, the importance of the age group and location factors for the use of the second person pronoun tu/você in Florianópolis-SC is discussed. Based on the concepts of Labov's (2008) Theory of Variation, the analysis of two semi-structured interviews with two Florianopolitans seeks to identify the linguistic and social factors that induce such linguistic phenomenon. Results from this case-study indicate variation in the use of $t u$ and você pronouns in the city. Moreover, the $t u$ pronoun is linked to their venacular while você is the pronoun choice for dealing with acquaintances or at the workplace, according to the participants.

Keywords: Sociolinguistics; second-person pronouns; tu/você variation.

\section{Introdução}

O português brasileiro (doravante PB) conta com duas ocorrências da forma pronominal da segunda pessoa do singular, tu e você (FRANCESCHINI, 2015; LOREGIAN-PENKAL, 2004; ROCHA, 2010; STRAPASSON; COELHO, 2013; TRAESEL, 2016). Sendo que há ainda a terceira variante possível, o pronome tu seguido de verbo conjugado na terceira pessoa do singular, como em: "tu fez, tu quer" (CEZARIO; VOTRE, 2008, p. 145). A variação no uso destas formas pronominais da segunda pessoa do singular chama atenção não somente dos brasileiros em geral, que tendem a reconhecer a variação como um traço regional, mas também de pesquisadores da área linguística. Tanto Cezario e Votre (2008) quanto Bagno (2007) ilustram que a variedade pronominal da segunda pessoa ocorre em diversos estados do Brasil, como por exemplo os estados do Rio de Janeiro e Maranhão. Em relação às pesquisas empíricas, uma breve busca no diretório da CAPES dos termos: variação tu e você lista 108 entradas com diversos artigos, dissertações e teses sobre o assunto, cujas analises fundamentam-se a partir das mais diversas varáveis: a influência da escolaridade e faixa etária em Franceschini (2015) e Rocha (2010), gênero em Strapasson e Coelho (2013) e área geográfica Franceschini (2015) e Traesel (2016). Estes estudos demonstram o forte interesse que tal fenômeno linguístico possui para a sociolinguística no Brasil.

Tendo em vista que a região sul do Brasil apresenta grande variabilidade no uso pronominal das formas tu e você (STRAPASSON; COELHO, 2013); e ainda, que a capital do estado de Santa Catarina, Florianópolis, oferece diversidade nesse uso (ROCHA, 2010; TRAESEL, 2016), o presente trabalho tem por objetivo oferecer uma análise do fator social faixa etária e localidade no uso dos pronomes pessoais tu e você por duas habitantes que nasceram e moraram em Florianópolis. 


\section{A VARIAÇÃO PELO VIÉS DA SOCIOLINGUÍSTICA}

Para a sociolinguística os fenômenos linguísticos são parte inerente do complexo organismo que é a língua. Há, a partir desta perspectiva, uma relação clara entre língua e sociedade, uma vez que a língua não é vista como um sistema homogêneo, mas que oferece variação natural pelo seu uso. Tal variação pode ser estudada, diferentemente do postulado por Sausurre, a partir de contextos reais de fala ou a indução da fala monitorada, por exemplo, analisando-se os diversos fatores que influenciam os fenômenos linguísticos. O estímulo para estudos linguísticos na sociolinguística é "que dada pessoa ou grupo usa a língua $X$ num contexto ou domínio Y" (LABOV, 2008, p.215). Desta forma, aspectos linguísticos e extralinguísticos ancoram a sociolinguística contemporânea.

Diferentemente do que apontavam os formalistas, que indicavam não ser possível o estudo da língua pelo alto grau de variabilidade da parole, Labov (2008) demonstra que há sistematicidade na variação e que é possível determinar a estrutura da linguagem a partir das mudanças que impactam esse organismo (LABOV, 2007, 2008). Estudos labovianos indicam que há diversas variáveis sociais que tendem a influenciar a linguagem, como por exemplo: sexo, idade, escolaridade, nível socioeconômico, contato com a escrita, contato com meios de comunicação em massa, etc.

Dentre as diversas variáveis socias que se relacionam com os fenômenos linguísticos, a faixa etária tem sido considerada fundamental (FRANCESCHINI, 2015). A idade do falante pode indicar que a mudança de um dado fenômeno linguístico está em progressão ou que atingiu estabilidade. Vale ressaltar que tal análise, pelo viés laboviano, deve considerar o contexto social no qual o fenômeno linguístico está inserido. Sendo assim, o contexto do presente estudo de caso é apresentado na sequência.

\section{A Variação Pronominal tu e você em Florianópolis}

Em sua obra mais popular, o preconceito linguístico, Bagno (2007) também trata da variação pronominal da segunda pessoa no PB. Embora o capítulo sobre esta variação foque na cidade de São Luiz do Maranhão, o autor também tece um breve comentário sobre a variação em Florianópolis, visto que ambas as cidades compartilharam forte imigração açoriana no passado. Segundo Bagno, o dialeto açoriano influenciou o PB falado nos dias de hoje nestas 
duas cidades.

Dentre os estudos analisados (FRANCESCHINI, 2015; LOREGIAN-PENKAL, 2004; ROCHA, 2010; STRAPASSON; COELHO, 2013; TRAESEL, 2016) que tratam da variação pronominal do tu e você para este estudo de caso; Rocha (2010) e Traesel (2016) analisaram a fala de habitantes de Florianópolis, bem como Loregian-Penkal (2004), cuja tese de doutorado de escopo mais amplo abarca também Florianópolis, portanto estes estudos são brevemente detalhados na sequência.

Loregian-Penkal (2004) analisou a variação pronominal no sul do país. Em relação aos dados da localidade Ribeirão da Ilha, em Florianópolis, 7 dos 11 informantes fizeram uso exclusivo do $t u$, enquanto os quatro restantes variaram o uso do tu e você com uma prevalência do tu. Em Florianópolis, como um todo, 13 participantes de um total de 24 fizeram uso exclusivo do $t u$, enquanto 10 alternaram entre tu e você e apenas um participante fez uso exclusivamente do pronome você. Em relação à flexão verbal, a pesquisadora indica que a flexão canônica seria a marca de identidade do habitante de Florianópolis, incluindo a localidade Ribeirão da Ilha. Vale ressaltar, ainda, que as mulheres favoreceram o uso do tu em comparação aos homens.

Historicamente é relatado que em Florianópolis usa-se a forma canônica do pronome tu com o verbo flexionado na segunda pessoa (ROCHA, 2010). Porém essa mesma autora reconhece que a "concordância com o tu apresenta significativa flutuação e, além disso, o você vem aparecendo em alguns contextos discursivos na fala dos manezinhos ${ }^{2 \prime \prime}$ (p. 70). Partindo da hipótese de que a forma canônica estaria mais presente na fala das comunidades de Ratones e Santo Antônio de Lisboa - ambas localidades tradicionais de Florianópolis - Rocha (2010) analisou dados das falas de oito entrevistados controlando duas variáveis: idade e escolaridade, segundo os preceitos da Teoria da Variação. Os resultados indicaram que a presença do tu ainda predomina nessas comunidades, com $97 \%$ das ocorrências; porém a forma canônica vem perdendo espaço, com apenas $11 \%$ das ocorrências. É relevante ressaltar que o uso da forma canônica parece estar ligado a certos verbos específicos como: estar, querer, saber, ir e ter.

Traesel (2016) usou metodologia similar à Rocha (2010), a Teoria da Variação e Mudança, para investigar a variação pronominal de tu e você no bairro Ingleses, na cidade de Florianópolis. Os participantes da pesquisa foram dez adolescentes que participaram de duas atividades: um debate e entrevistas individuais que foram transcritos e quantificados. Os resultados indicaram que os jovens quando entrevistados usaram o pronome tu e suas formas relacionadas (possessivo e oblíquo) em $61 \%$ das ocorrências da segunda pessoa pronominal e

${ }^{2}$ Nomenclatura usada para se referir a/o habitante nativa/o da ilha de Florianópolis. 
que mais de $90 \%$ da conjugação verbal com tu teve a forma verbal não canônica (e.g., "tu come"). É importante ressaltar que houve uma diferença significativa na porcentagem do uso de tu e você quando os dados dos participantes nativos foram comparados aos não-nativos. Em outras palavras, os nativos de Florianópolis usaram o tu preferencialmente.

Tendo em vista que os resultados dos dois estudos analisados apontaram um variado uso pronominal em Florianópolis em três localidades distintas (Santo Antônio de Lisboa, Ratones e Ingleses), o objetivo deste estudo de caso é analisar a possível variação pronominal no uso de tu e você com duas participantes de Florianópolis cuja diferença de idade é de 34 anos. Com base nos estudos apresentados, esta pesquisa tem como hipótese o uso do pronome tu com verbo seguido da forma não canônica pelas participantes. Na sequência detalha-se o método empregado para alcançar tal objetivo.

\section{Método}

\subsection{Participantes}

Duas habitantes de Florianópolis foram convidadas a participar da pesquisa. Foi explicado que por questões de influência nas respostas o propósito da pesquisa seria revelado apenas após a entrevista. Da mesma forma, explicou-se verbalmente às participantes o anonimato garantido; logo, cada participante pôde escolher um pseudônimo. Uma breve descrição das participantes é apresentada a seguir.

Pretty - tem 18 anos e é estudante universitária. Viveu sua infância em Biguaçu, município da região metropolitana localizado ao norte de Florianópolis. Depois, a família mudou-se para Barreiros, que é um bairro de São José próximo a parte continental de Florianópolis. Por fim, no início da adolescência, sua família mudou-se para o Ribeirão da Ilha onde reside hoje.

Marcela - tem 52 anos, possui o nível superior incompleto. Nasceu e sempre viveu na região central de Florianópolis onde também trabalha. Marcela é secretária de uma escola pública.

\subsection{Instrumento e Coleta de Dados}

A fim de fomentar o uso pronominal da segunda pessoa do singular uma entrevista semiestruturada (DÖRNYEl, 2007) foi elaborada (ver anexo 1). Segundo Dörnyei (2007), este tipo de entrevista representa um meio termo em termos de flexibilidade "embora haja um 
esquema prévio com perguntas, esse formato é semiaberto, sendo que o/a entrevistado/a é estimulado/a a contribuir com as questões abordadas de forma exploratória ${ }^{3 \prime \prime}$ (p. 136, tradução minha). Esta pesquisa também tem por suporte princípios da metodologia variacionista, pois faz uso - mesmo que em pequena escala - de narrativas de experiência pessoal, como apontam Strapasson e Coelho (2013). A escolha pela entrevista semiestruturada com questões justifica-se pela escassez de tempo para a pesquisa, uma vez que a coleta de fala espontânea demandaria muito tempo. Essa entrevista seguiu recomendações da área sociolinguística que prevê o início da fala numa entrevista como um período que necessita de acomodação para, na sequência, instigar o uso mais próximo do "natural" pelo/a entrevistado/a, seguido das perguntas relacionadas ao objetivo do estudo.

As entrevistas foram feitas usando um aparelho de celular (One Plus3) e o aplicativo Voice Recorder para gravar as falas.

\section{Resultados e Discussão}

As entrevistas foram transcritas a fim de quantificar as ocorrências das três variáveis alvo: (1) tu seguido de verbo conjugado na segunda pessoa singular, que é a forma canônica (e.g., "tu sabes"), (2) tu seguido de verbo conjugado na terceira pessoa do singular (e.g., "tu sabe") e, finalmente, (3) você seguido de verbo conjugado na terceira pessoa singular (e.g., "você sabe"). O agrupamento destes resultados é apresentado na sequência.

${ }^{3}$ Do original: "although there is a set of pre-prepared guiding questions and prompts, the format is open-ended and the interviewee is encouraged to elaborate on the issues raised in an exploratory manner" 
4.1 Apresentação e análise dos dados da participante Pretty

Gráfico 1: Uso pronominal: participante Pretty

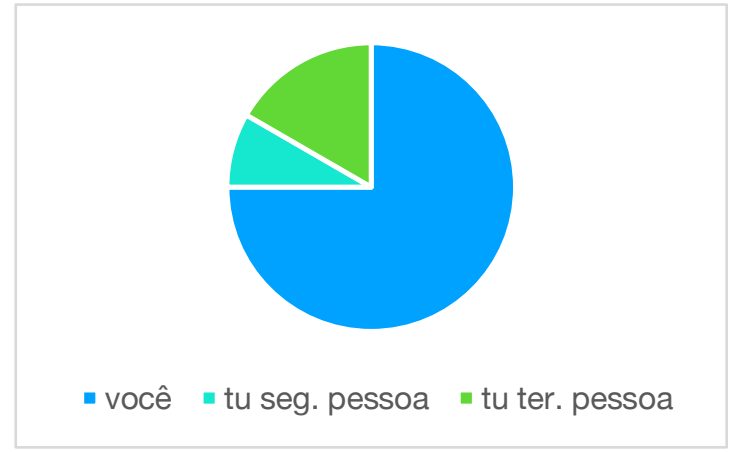

O gráfico 1 ilustra a presença majoritária do pronome você na fala de Pretty. Este pronome apareceu em 75\% das ocorrências (9), seguido do pronome $t u$ + verbo conjugado na terceira pessoa com 16,7\% (2), e 1 ocorrência (8,3\%) da forma canônica do pronome tu + verbo conjugado na segunda pessoa.

Tendo em vista que Pretty reside no Ribeirão da Ilha, tradicional bairro de imigração açoriana, esperava-se que houvesse uma maior presença no uso do pronome tu. De certa forma, este resultado vai de encontro à Rocha (2010), cujos dados colhidos em duas comunidades semelhante ao Ribeirão da Ilha encontrou o uso majoritário do pronome tu. A fala de Pretty, com variação no uso pronominal, assemelha-se a fala de alguns participantes de LoregianPenkal (2004) na mesma localidade, Ribeirão da Ilha, embora haja uma inversão da prevalência do você na fala de Pretty. Levando-se em conta que na pesquisa de Rocha nenhum participante mais jovem (menor que 35 anos) utilizou o pronome você, os dados colhidos com Pretty, que tem 18 anos, tendem a demonstrar uma grande diferença. Uma das razões para esta diferença pode ser atribuída ao fato de Pretty ter nascido em Biguaçu, região metropolitana de Florianópolis, e ter mudado para o Ribeirão da Ilha no início de sua adolescência. No entanto, Biguaçu está localizada próximo à Florianópolis e muitos moradores desse município trabalham e ou estudam na ilha. Este fato faz a análise do uso dos pronomes possessivo e clítico por Pretty ainda mais necessária. 
Gráfico 2: Uso do possessivo: participante Pretty

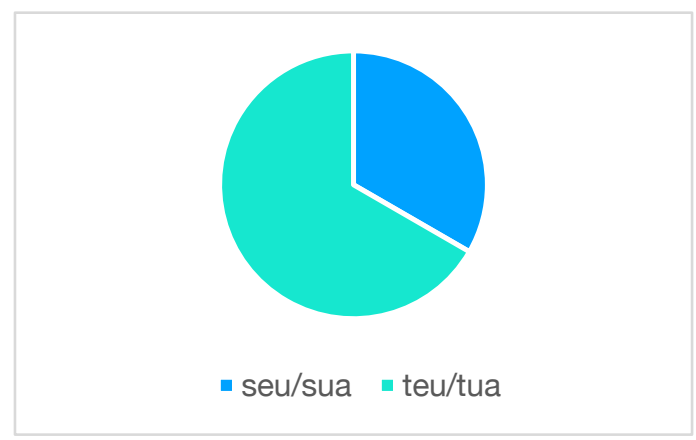

O gráfico 2 apresenta os dados do uso dos pronomes possessivos teu/tua versus seu/sua que estão ligados às respectivas formas pronominais tu e você. Os pronomes teu/tua foram utilizados quatro vezes (67\%), enquanto o uso de seu/sua ficou restrito a duas (33\%) ocorrências. Quando cruzados os dados dos gráficos 1 e 2, os resultados parecem ser conflitantes. Uma vez que o uso de teu/tua, bem como as formas oblíquas te/ti, normalmente estão correlacionados ao uso de tu no fenômeno linguístico conhecido como paralelismo (TRAESEL, 2016). No caso de Pretty, um fator que pode ser um indicativo da razão dessa incongruência é encontrado na resposta dada à pergunta final da entrevista. Pretty relatou que sua mãe costumava dizer que o uso do pronome tu é "feio" e que não seria apropriado para o uso com "pessoas mais velhas". Ademais, Pretty informou que durante a entrevista monitorou sua fala em algumas ocasiões para não falar $t u$. Assim, pode-se talvez atribuir a maior presença percentual de você, $75 \%$ de ocorrências, ao seu auto monitoramento. Por outro lado, o pronome possessivo, por aparentemente sofrer menor monitoramento, apresentou um número mais elevado de ocorrências da forma teu/tua em relação a seu/sua. Segundo a participante, o pronome tu está relacionado ao seu vernáculo. Na sequência, os dados da segunda participante dessa pesquisa são apresentados. 


\subsection{Apresentação e análise dos dados da participante Marcela}

Gráfico 3: Uso pronominal: participante Marcela

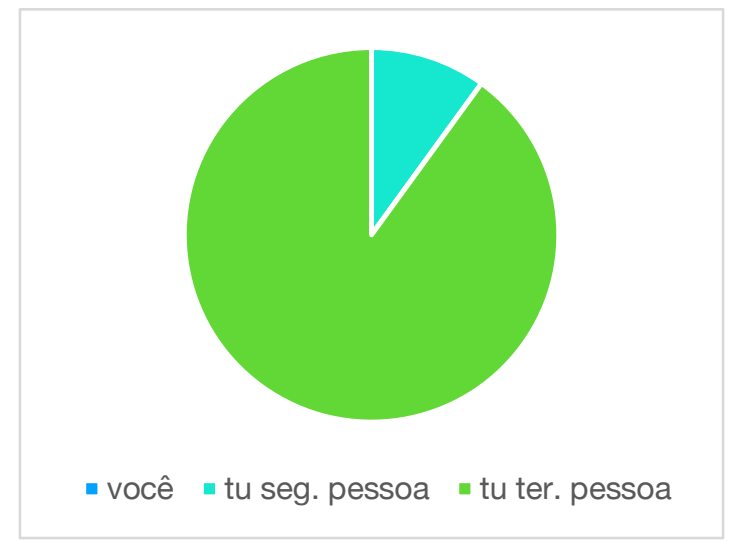

O gráfico 3 ilustra a presença única do pronome tu na fala de Marcela. Este pronome apareceu em 100\% das ocorrências, sendo que em 9 ocasiões (90\%) ele foi seguido de verbo conjugado na terceira pessoa e apresentou uma única ocorrência (10\%) da forma canônica do pronome $t u+$ verbo conjugado na segunda pessoa.

A fala de Marcela indica uma relação mais próxima com os dados de pesquisas anteriores feitas com habitantes de Florianópolis (ROCHA, 2010, TRAESEL, 2016), pois a participante fez uso exclusivo do $t u$. Houve duas formas deste uso, sendo a forma não canônica mais presente. Este fato é relevante pois assemelha-se aos valores encontrados por Rocha (2010). Os participantes de Rocha também usaram majoritariamente o tu e, em quantidade significativa, fizeram uso da forma não canônica na maior parte das realizações "o pronome tu com concordância foi encontrado em apenas 14 ocorrências (11\%)" (ROCHA, 2010, p. 78), valores estes similares a fala de Marcela. No presente estudo, Marcela somente usa a forma canônica uma vez "Tens irmãos?", com a forma pronominal apagada. É interessante ressaltar que 'ter' é um dos verbos que segundo Rocha (2010) fomenta o uso da forma canônica, este fenômeno já tinha sido observado na fala de Pretty "Tu tens alguma coisa pra me emprestar?" o que parece corroborar essa proposição levantada por Rocha.

Uma possível explicação para a variante não canônica usada por Marcela é que a participante, diferentemente da maioria dos participantes de pesquisas semelhantes, não nasceu 
ou morou em bairros de Florianópolis tradicionalmente ligados à imigração açoriana. Por morar no centro de Florianópolis e trabalhar em uma escola, Marcela está em contato com muitos falantes de PB que não são nativos da ilha. Em seguida, é apresentado o gráfico com os dados do uso dos pronomes possessivo e clíticos por Marcela.

\section{Gráfico 4: Uso do possessivo: participante Marcela}

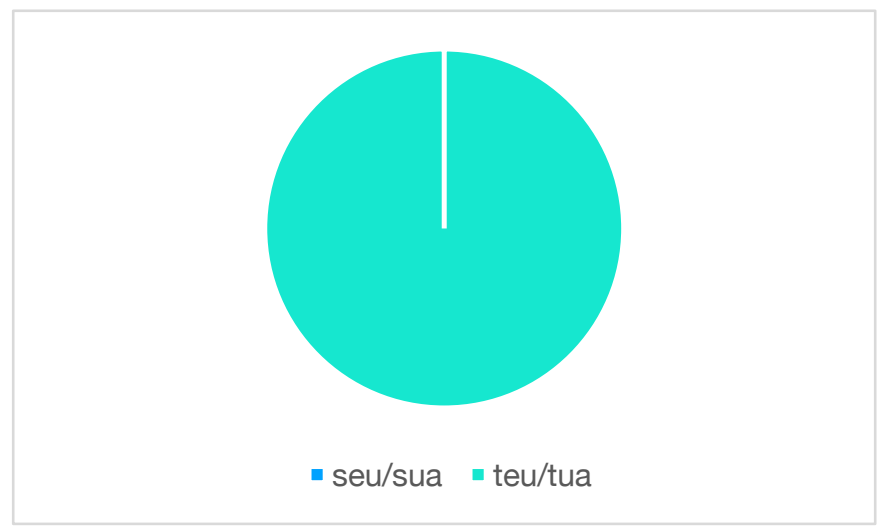

O uso do pronome possessivo por Marcela, gráfico 4, mostrou-se consistente com o uso do pronome $t u$. Houve duas ocorrências $(100 \%)$ de uso de teu/tua. Houve também uma ocorrência do pronome oblíquo te e uma do pronome oblíquo ti. De uma certa forma, pode-se deduzir que a fala de Marcela foi menos monitorada que a fala de Pretty.

Finalmente, é válido ressaltar que Marcela considera o uso de tu informal. No seu trabalho, a escola, ela afirma ter que usar o pronome você por necessitar uma certa distância no atendimento às pessoas.

Bagno (2007), de forma drástica, afirma que o pronome tu tende a desaparecer no PB. Embora a população de Florianópolis tenha certa semelhança com a ilha de Martha's Vinyeard, estudada por Labov (TRAESEL, 2016), com um grande influxo de visitantes no verão. Florianópolis também conta com um grande número de pessoas que decidiram mudar-se para a cidade recentemente. Embora a presença destes habitantes pareça impactar, de certa forma, o falar em Florianópolis, uma vez que Pretty afirma que foi através do contato com sua amiga de Curitiba que: "Eu aprendi a falar você há uns 2 anos com uma amiga de Curitiba". Os dados analisados não indicam que essa extinção do pronome tu tenda a ocorrer em breve em Florianópolis. Pelo contrário, as participantes indicaram que o pronome tu é a forma mais 
próxima do seu vernáculo e, como Traesel (2016) relata, este uso está relacionado à imagem de ser manezinho/a.

\section{CONSIDERAÇÕES FINAIS}

Apesar de ser um estudo de caso restrito, os dados desta pesquisa permitem certas conclusões. Primeiramente, parte dos dados vão de encontro à Rocha (2010) que focou em bairros de imigração açoriana. A participante mais jovem deste estudo demonstrou uma variação maior no uso pronominal da segunda pessoa, já a fala de Marcela encontra semelhança à pesquisa de Rocha. De certa forma, os resultados aproximam-se mais aos encontrados por Traesel (2016), logo a hipótese inicial foi confirmada, ou seja, tu seguido pela forma não canônica verbal predominou nos dados coletados. Este fato pode ser explicado por dois fatores, em primeiro lugar uma das participantes sempre morou na região central, enquanto a participante do Ribeirão da Ilha morou poucos anos naquele bairro. Além disso, é importante ressaltar que a fala de Pretty pareceu estar mais monitorada do que a fala de Marcela devido a sua alternância de estilo. É difícil, pelo número reduzido de participantes, afirmar que a idade foi um fator determinante para a diferença pronominal observada, porém os resultados indicam uma variação pronominal distinta de estudos anteriores e contribui no que toca à continuação da investigação da variação dos pronomes tu e você em Florianópolis.

Um fator a ser ressaltado ainda é a mudança do status do bairro Ribeirão da Ilha desde o estudo de Loregian-Penkal em 2004. Se naquele ano, o bairro podia ser considerado isolado e uma comunidade, de certa forma, à parte de Florianópolis devido ao baixo investimento no turismo (LOREGIAN-PENKAL, 2004). A recente mudança do bairro, com a valorização do Ribeirão da Ilha como zona turística e gastronômica tem alterado o tecido social atraindo novos habitantes para a localidade. Pretty, dessa forma, é representante desta nova configuração social local.

\section{Limitações e sugestões para novas pesquisas}

É importante mencionar as limitações que o presente estudo de caso oferece. O primeiro diz respeito a quantidade de informantes, o fato de ter apenas duas entrevistadas faz com que a generalização dos resultados seja muito restrita. Segundo, a utilização de uma entrevista semiestruturada não reflete necessariamente o uso espontâneo da fala. Por fim, a fala 
gravada muitas vezes pode inibir o/a entrevistado/a e, da mesma forma que a entrevista, pode não refletir o vernáculo do/a participante, uma vez que o monitoramento da fala tende a estar presente.

Finalmente, ressaltam-se dois aspectos para pesquisas futuras. Primeiro, a fala de moradores do centro da cidade poderia ser analisada por pesquisas sociolinguísticas, tendo em vista que a maioria das pesquisas semelhantes realizadas em Florianópolis focaram em bairros longe do centro. $\mathrm{O}$ centro, principalmente a parte mais antiga próxima à praça $\mathrm{XV}$, tem uma longa história de mudanças sociais e urbanas; logo, pesquisas de cunho sociolinguístico nessa região poderiam ajudar a entender as mudanças pelas quais esta região tem passado. Segundo, futuros estudos na região do Ribeirão da Ilha poderão indicar se a variação pronominal está em processo de mudança por conta da valorização turística local. Como Naro e Scherre (1991) apontam, ao mesmo tempo numa mesma localidade, uma comunidade de fala pode estar caminhando em diversas direções. Novas pesquisas na região poderão trazer mais dados a fim de indicar para qual direção o fenômeno linguístico da variação pronominal da segunda pessoa segue na região.

\section{Referências}

BAGNO, M. Preconceito lingüístico - o que é, como se faz. 49 ed. Loyola: São Paulo. 2007.

CEZARIO, M. M.; VOTRE, S. Sociolinguística. In: MARTELOTTA, M.E. (Ed.) et al. Manual de Linguística. São Paulo: Contexto, 2008, p.XXX-XXX.

DÖRNYEI, Z. Research Methods in Applied Linguistics: Quantitative, qualitative and mixed methodologies. UK: Oxford University Press. 2007.

FRANCESCHINI, L. T. Variação pronominal tu/você em Concórdia-SC: o papel dos fatores sociais. Revista Signótica, v. 27, n.2, p.265-286. 2015

LABOV, W. Padrões Sociolinguísticos. Tradução de Marcos Bagno Marta Scherre e Caroline Cardoso. São Paulo: Parábola, 2008

LABOV, W. Sociolinguística: uma entrevista com William Labov. Tradução de Gabriel de Ávila Othero. Revista Virtual de Estudos da Linguagem - ReVEL, v. 5, n. 9, agosto de 2007.

LOREGIAN-PENKAL, L. (Re)análise da referência de segunda pessoa na fala da região Sul. Tese (Doutorado em Letras) - Programa de Pós-Graduação em Letras, Universidade Federal do Paraná, 2004.

NARO, A. J.; SCHERRE, M. M. P. Variação e mudança linguística: fluxos e contrafluxos na comunidade de fala. Cadernos de Estudos Lingüísticos, Campinas, SP, v. 20, p. 9-16, out. 2012. ISSN 2447-0686. Disponível em: <https://periodicos.sbu.unicamp.br/ojs/index.php/cel/article/view/8636853>. Acesso em: 30 dez. 2018. doi:https://doi.org/10.20396/cel.v20i0.8636853. 
ROCHA, P. G. A variação dos pronomes de segunda pessoa na língua falada nas comunidades de Ratones e Santo Antônio de Lisboa - Uma abordagem sociolinguística variacionista. Working Papers em Linguística, v. especial, p.69-81. 2010.

STRAPASSON, G. E. R. F.; COELHO, I. L. Presença dos pronomes pessoais tu / você nós / a gente na narrativa de experiência pessoal nos indivíduos da cidade de Caçador - Santa Catarina. Revista Professare. v.2, n.1, p. 53-72. 2013.

TRAESEL, R. As formas varáveis de tratamento ao interlocutor da ilha de Santa Catarina: estudo de fala de adolescentes dos Ingleses. Dissertação (Mestrado em Linguística) - Universidade Federal de Santa Catarina. Florianópolis, 2016. 


\section{Anexo 1 - Roteiro da Entrevista}

Já gravando.

Me conte rapidamente como foi seu dia. (ice-breaker)

Me diga, quando você era criança quais ordens sua mãe te dava? O que ela falava pra você? Me de exemplos?

Você tem contato com crianças pequenas? Como você acha importante pedir/ dar ordens hoje em dia para elas? Me de exemplos.

Obrigado.

Você lembra as 2 perguntas? (caso a entrevistada não lembre eu posso falar: ordens que minha mãe me dava e ordens/ pedidos para as crianças de hoje em dia). Você pode me fazer as mesmas perguntas, por favor?

Você pode fazer algumas perguntas (2 ou 3) pra mim sobre a minha infância, por favor.

Ok, muito obrigado.

Para finalizar, gostaria de perguntar uma coisa. Você considera usar os 2 pronomes 'tú' e 'você' no dia-a-dia? Eles têm alguma diferença no uso para você?

Paro a entrevista/gravação e explico o propósito da pesquisa.

Recebido em 16/01/2019.

Aprovado em 23/05/2019. 